\title{
Prediction of pain in orthodontic patients based on preoperative pain assessment
}

\author{
This article was published in the following Dove Press journal: \\ Patient Preference and Adherence \\ 3 March 2016 \\ Number of times this article has been viewed
}

\section{Baoyu Zheng' \\ Manman Ren ${ }^{2}$ \\ Feiou $\operatorname{Lin}^{3}$ \\ Linjie Yao ${ }^{4}$}

'Periodontic Department, ${ }^{2}$ Oral and Maxillofacial Surgery Department, School and Hospital of Stomatology, ${ }^{3}$ Orthodontic Department,

${ }^{4}$ Pedodontic Department, School and Hospital of Stomatology, Wenzhou

Medical University, Wenzhou, Zhejiang,

People's Republic of China
Correspondence: Linjie Yao Pedodontic Department, School and Hospital of Stomatology, Wenzhou Medical University, No II 3 West

Xueyuan Road, Wenzhou, Zhejiang,

People's Republic of China

Tel/fax +8657788063008

Email yaolinjiesci@।63.com
Aim: To investigate whether pretreatment assessment of experimental pain can predict the level of pain after archwire placement.

Methods: One hundred and twenty-one general university students seeking orthodontic treatment were enrolled in this study. A cold pressor test was performed to estimate the pain tolerance of subjects before treatment. Self-reported pain intensity was calculated using a $10 \mathrm{~cm}$ visual analog scale during the 7 days after treatment. The relationship between pain tolerance and orthodontic pain was analyzed using Spearman's correlation analysis.

Results: The maximum mean level of pain intensity occurred at 24 hours after bonding $(53.31 \pm 16.13)$ and fell to normal levels at day 7. Spearman's correlation analysis found a moderate positive association between preoperative pain tolerance and self-reported pain after archwire placement $(P<0.01)$. There was no significant difference in pain intensity between male and female patients at any time point $(P>0.05)$.

Conclusion: A simple and noninvasive preoperative sensory test (the cold pressor test) was useful in predicting the risk of developing unbearable pain in patients after archwire placement. Self-reported pain after archwire placement decreased as individual pain tolerance increased.

Keywords: cold pressor test, intensity, self-reported

\section{Introduction}

Mild-to-severe acute pain occurs in $>90 \%$ of patients undergoing orthodontic treatment. ${ }^{1,2}$ Despite the developing technology in orthodontics, most patients still experience some discomfort or pain in relation to orthodontic treatment, especially during the 7 days after archwire placement. ${ }^{3}$ The reasons for the wide variation in patients' experience of pain after similar types of orthodontic treatment have been widely discussed. It is believed that the experience of pain consists of sensory perceptions of intensity and discomfort and can also be influenced by cognitive, emotional, and environmental factors. ${ }^{4,5}$ Previous researchers attributed the immediate and delayed pain response to inflammatory reactions causing changes in blood flow following orthodontic force application. This procedure makes the periodontal ligament sensitive to released algogens such as histamine, prostaglandins, bradykinin, and serotonin. ${ }^{6,7}$ The increased levels of these mediators elicit a pain response following orthodontic force application.

Various methods of pain control have been developed for use during orthodontic treatment, including nonsteroidal anti-inflammatory drugs (NSAIDs) ${ }^{8}$ low-level laser therapy, ${ }^{9,10}$ transcutaneous electrical neural stimulation, ${ }^{11}$ and vibratory stimulation. ${ }^{12}$ Until now, the use of NSAIDs has been the preferred and most successful method of pain control. However, NSAIDs may cause side effects, including thrombocytopenia, 
headaches, and skin rashes. It is important to estimate the level of personal pain perception to gage how well a patient will tolerate postoperative pain in orthodontics. This may help the orthodontist select an appropriate method of pain control that tailors the risk-benefit ratio of using NSAIDs in particular patients. As a result, some patients could require lower doses of analgesic drugs with a lower risk of side effects. Nevertheless, prediction of pain is difficult because of various influencing factors. Some previous researchers have studied the relationship between orthodontic pain and psychological factors or personality traits, ${ }^{13,14}$ but such studies require extensive resources to collect and analyze the data for each patient. Furthermore, the reliability and validity of psychological assessment are difficult without the professional assistance of a psychologist.

The aim of this study was to investigate whether pretreatment assessment of experimental pain perception using a cold pressor test could predict the level of pain after archwire placement.

\section{Methods}

Ethical approval for the study was granted by the Health Research Ethics Board at Wenzhou Medical University. Each patient was given oral and written information and signed a written consent form before participating in the study.

The research was designed as a prospective study. A total of 121 general university students seeking orthodontic treatment were recruited from the Orthodontic Department of Wenzhou Medical University, Wenzhou, People's Republic of China, between January 2014 and May 2015. The following exclusion criteria were applied: had undergone previous orthodontic treatment, was currently taking any antibiotics or analgesics, had a systemic disease, had third molars extracted, or experienced anxiety (trait anxiety inventory score: male patients $\geq 56$ and female patients $\geq 57$ or state anxiety inventory score: male patients $\geq 53$ and female patients $\geq 55$ ). All patients had moderate crowding (4-8 $\mathrm{mm}$ according to Little's irregularity index) and agreed to have orthodontic treatment with fixed upper and lower appliances $\left(0.022 \times 0.028\right.$ inch, Victory Series ${ }^{\mathrm{TM}}$; $3 \mathrm{M}$ Company; Maplewood, MN, USA). Tooth alignment and leveling began with a 0.012-inch nickel-titanium archwire (Grikin Advanced Materials Co. Ltd, Beijing, People's Republic of China), and the ligation was performed by one trained orthodontist using AlastiK ${ }^{\mathrm{TM}}$ (3M Unitek). All subjects needed four first premolars extracted. The right upper and lower premolars were extracted first, and the left upper and lower premolars were extracted 1 week later. All premolars were successfully extracted within 5 minutes after anesthesia. The archwire was placed at least 2 weeks after the extractions.

Before extraction of the premolars, a cold pressor test was performed to assess pain tolerance by measuring the time of immersion (in seconds) of the subject's hand in ice water. All subjects were informed that the maximum test duration would be 240 seconds, and they were asked to remove their hand when they could no longer tolerate the pain. Cold water and ice cubes (v:v, $2: 1$; temperature, $\left.0^{\circ} \mathrm{C}-1^{\circ} \mathrm{C}\right)$ were mixed 15 minutes before testing in an isolated tank. To ensure uniform temperature distribution within the tank, the mixture was stirred immediately before the test. A thermometer was placed in the water so that the water temperature could be monitored and maintained at $0^{\circ} \mathrm{C}-1^{\circ} \mathrm{C}$. Subjects were asked to immerse their nondominant hand with the palm gently resting on the bottom of the tank. ${ }^{15}$ An isolated room was used to ensure that subjects were not distracted and that the examiner did not communicate with the subjects verbally or nonverbally. The subjects were asked to rate the intensity of the most intense pain felt during the immersion period on a visual analog scale (VAS) record immediately after removing their hand from the water or after the maximum exposure of 240 seconds.

The state-trait anxiety inventory was used preoperatively to assess subjects' anxiety before entering the dentist's room. The test was conducted by the same investigator for all patients.

The participants were asked to report pain intensity by completing a VAS questionnaire at the first visit and 24 hours after the premolars were extracted. This take-home questionnaire consisted of a $10 \mathrm{~cm}$ line, and subjects were asked to mark a location on the line corresponding to the highest pain intensity experienced during the 24 hours after the extractions, from no pain " 0 " to severe/unbearable pain "100". Subjects with baseline pain intensity ratings $<5 \mathrm{~mm}$ were included. Then, the participants were asked again to complete the VAS questionnaire before bonding as "zero time" (T0), 24 hours after bonding (T1), 2 days after bonding (T2), 4 days after bonding (T3), and 7 days after bonding (T4). During the period of investigation, patients were asked to eat soft foods and not to use analgesics unless they were experiencing unbearable pain. All participants were informed of the possible occurrence of pain, ulcers, and difficulty in chewing.

Statistical Package for the Social Sciences (SPSS for Windows, version 15.0; SPSS Inc., Chicago, IL, USA) was used to analyze the research data. The Kolmogorov-Smirnov test was used to verify the distribution of the data. Variables 
with asymmetrical distribution were described using the median and interquartile range. The relationship between the experimental pain perception and orthodontic pain was analyzed using Spearman's correlation analysis. The Wilcoxon signed-rank test was performed to observe differences between male and female patients. Comparisons between the different times were performed using the Friedman test. The results were evaluated within a $95 \%$ confidence interval. The statistical significance level was established at $P<0.05$.

\section{Results}

Nine patients used analgesics during the research, and eight patients quit or did not finish the questionnaire. Finally, a total of 121 subjects were recruited for the present research. The demographic characteristics of the participants are shown in Table 1. Eleven participants immersed their hand for the maximum test duration. The mean (interquartile range) preoperative pain tolerance of male and female patients was 71.3 (57-116) and 53.1 (35-81), respectively. Male patients had significantly better tolerance than female patients $(P<0.01)$. The self-reported pain intensity during the cold pressor test was $65.13 \pm 19.26$. There was no statistically significant sex difference in reported pain intensity during the cold pressor test $(P=0.12)$. The state and trait anxiety scores in subjects were $38.83 \pm 5.02$ and $38.12 \pm 4.82$, respectively.

Pain intensity as reported by subjects on a VAS (0-100) from extraction to orthodontic treatment is shown in Table 2. The Kolmogorov-Smirnov test showed that pain intensity only exhibited a normal distribution at T1, T2, and T3. Spearman's correlation coefficient between preoperative

Table I Demographic characteristics of the subjects

\begin{tabular}{ll}
\hline Demographics & $\mathbf{N}$ \\
\hline Sex & \\
Male & 51 \\
Female & 70 \\
Age, years & \\
$<18$ & 5 \\
I8-2I & 108 \\
$>2$ I & 8 \\
Regional & \\
Zhejiang province & 68 \\
Other provinces & 53 \\
Crowding, mm & \\
4-8 & 121 \\
Malocclusion & \\
Class I & 43 \\
Class II & 63 \\
Class III & 15 \\
Total & 121 \\
\hline
\end{tabular}

pain tolerance scores and the highest pain experienced after extraction $(r=0.57 ; P<0.01)$, pain intensity at T1 $(r=0.71$; $P<0.01)$, T2 (r=0.69; $P<0.01)$, T3 ( $r=0.73 ; P<0.01)$, and T4 $(r=0.62 ; P<0.01)$ was significant, indicating a moderate positive association between preoperative pain tolerance scores and pain after archwire placement.

Differences in pain intensity at each time point after archwire placement are shown in Figure 1. The maximum mean level of pain intensity occurred at 24 hours after bonding (53.31 \pm 16.13$)$, and then the pain gradually reduced. Figure 2 shows the distribution of participants according to pain intensity and preoperative pain tolerance. Only one participant, who had a pain tolerance of $>90$ seconds in the cold pressor test, completed the VAS questionnaire with a score of $>70$. There was no significant difference in reported pain intensity between male and female patients at any time point $(P>0.05)$.

\section{Discussion}

Different preoperative sensory tests have been shown to predict postoperative pain. ${ }^{16-19}$ Among these tests, the cold pressor test provides a valid and low-risk test for evaluating pain in patients and has been routinely used in pain research. This study was the first to use a cold pressor test as a preoperative pain assessment method to predict pain in orthodontic patients from East China and found a moderate positive association between preoperative pain tolerance scores and pain after archwire placement.

All participants included in this study were students with similar psychosocial characteristic and treatment plans; this design could have decreased the influence of cognitive differences, which might have affected pain perception. The cognitive component of pain includes attentional processes, anticipation, and memory of past experiences of pain. ${ }^{20}$ Many affective states, including anxiety, fear, depression, stress, and panic, are potentially important in the experience and expression of pain. ${ }^{21}$

In the cold pressor test, the water temperature was monitored and sustained at $0^{\circ} \mathrm{C}-1^{\circ} \mathrm{C}$, because a $2^{\circ} \mathrm{C}$ difference in temperature can affect tolerance time and pain intensity. ${ }^{19}$ The painful sensation was determined by a multitude of factors that included objective and subjective domains. It would be difficult to use a cross-sectional study to control impact factors of pain perception; therefore, we chose a self-controlled study to examine the prediction of pain in orthodontic patients. Most of the previous studies have focused on the sensory aspect of pain, asking participants to report pain intensity using the VAS, ${ }^{13,22,23}$ which has been 
Table 2 Pain intensity on a visual analog scale (0-100) from extraction to orthodontic treatment

\begin{tabular}{llll}
\hline Time & $\begin{array}{l}\text { Pain intensity, median } \\
\text { (interquartile range) }\end{array}$ & $\begin{array}{l}\boldsymbol{r} \text { with preoperative } \\
\text { pain tolerance }\end{array}$ & $\begin{array}{l}\text { Kolmogorov-Smirnov test } \\
(\boldsymbol{P})\end{array}$ \\
\hline $\begin{array}{l}\text { Preoperative pain } \\
\text { tolerance (seconds) }\end{array}$ & $60.5(48-90)$ & None & 0.032 \\
$\begin{array}{l}\text { Highest pain experienced } \\
\text { after extraction }\end{array}$ & $42.41(36-46.5)^{* *}$ & 0.57 & 0.02 \\
T0 & $2.61(1-3)$ & & 0.001 \\
T1 & $53.31(43-66.5)^{* *}$ & 0.10 & 0.29 \\
T2 & $43.21(33-55.5)^{* *}$ & 0.71 & 0.32 \\
T3 & $26.57(16.5-35)^{* *}$ & 0.69 & 0.45 \\
T4 & $8.58(2-12)^{* *}$ & 0.73 & 0.001 \\
\hline
\end{tabular}

Notes: Preoperative pain tolerance (seconds) compared with other groups, **significant at $P<0.0 \mathrm{I}$. Before bonding (T0), 24 hours after bonding ( $\mathrm{TI}$ ), 2 days after bonding (T2), 4 days after bonding (T3), and 7 days after bonding (T4).

found to be reliable and valid; ${ }^{24,25}$ therefore, we also used it in this study.

An important limitation of previous studies of pain in orthodontics is that the orthodontic treatment procedures are usually not controlled, and various procedures may be performed. In this study, standardized procedures and materials were used by one researcher. Specifically, the standard procedure consisted of extracting four first premolars, placing an archwire, and performing ligation. It has been reported that subjects with superelastic nickel-titanium archwires experience significantly higher pain than those with multistranded stainless steel archwires at the peak level. ${ }^{26} \mathrm{~A}$ randomized clinical trial found that self-ligating brackets resulted in lower pain intensity than conventional twin brackets ${ }^{27}$ however, a systematic review of self-ligating bracket studies concluded that currently there is insufficient evidence to support significant differences in subjective pain experience between self-ligating and conventional appliances. ${ }^{28}$
Differences in pain perception between male and female patients have been increasingly studied in recent years. Mitchell et al ${ }^{19}$ and Riley et al observed sex differences, with men having better tolerance for pain stimuli than women. ${ }^{29}$ A similar phenomenon was observed in this study. It is generally assumed that gonadal hormones contribute to greater clinical and experimental pain experiences in female patients as compared with male patients. ${ }^{30}$ However, inconsistent findings have been reported in more recent studies. ${ }^{31,32}$ In the orthodontic literature, some studies comparing pain perception with fixed appliances found that male patients reported lower pain intensity than female patients, ${ }^{1,33}$ while others found no statistically significant differences between sexes, ${ }^{34,35}$ and the latter case prevailed in our study. This finding may be related to the different study design and inclusion criteria of the participants. The maximum mean pain for subjects peaked at 24 hours, as reported in the previous research. ${ }^{26}$ The mean preoperative pain tolerance of

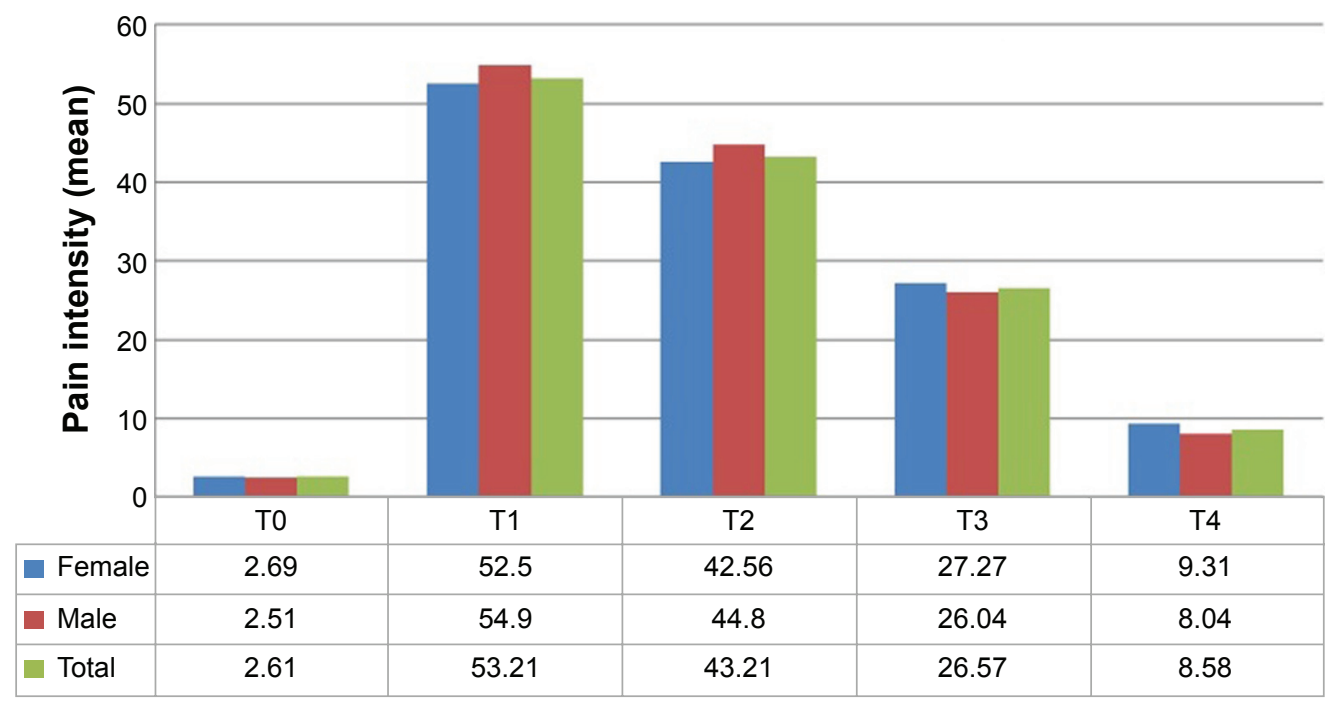

Figure I Pain intensity at each time point as reported by subjects using a $10 \mathrm{~cm}$ visual analog scale. Note: Before bonding (T0), 24 hours after bonding (TI), 2 days after bonding (T2), 4 days after bonding (T3), and 7 days after bonding (T4). 


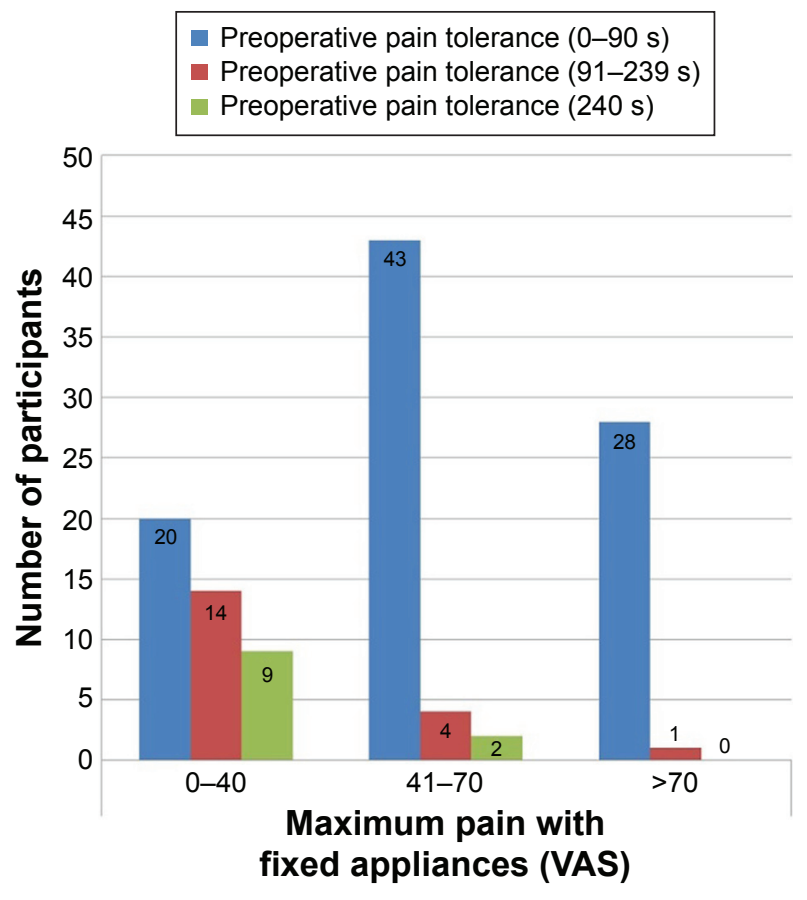

Figure 2 The distribution of participants according to pain intensity and preoperative pain tolerance.

Abbreviations: VAS, visual analog scale; s, seconds.

nine subjects who used analgesics during the research was 28.3 (range: 11-39), which is much lower than the normal mean value. The results of this research could help dentists use analgesic drugs more effectively and reasonably, and patients at high risk for pain might benefit from preemptive analgesic interventions. Conversely, patients at low risk could manage with less or no analgesic medication.

\section{Limitations}

A limitation of this study is that psychosocial metrics were not taken at the time of the cold pressor test, prior to extraction, postextraction, or at archwire bonding to ensure that the subjects were experiencing the same trait at each event; this may have influenced the results for self-reported pain. This study cannot completely explain the variable experiences of orthodontic pain because of the small sample. Therefore, further research involving larger samples is needed to obtain a more comprehensive result, together with analysis of other contributing factors such as anxiety and gonadal steroid hormones.

\section{Conclusion}

This research used a simple and noninvasive preoperative sensory test (the cold pressor test) to investigate the relationship between experimental pain and self-reported pain after archwire placement. The self-reported pain after archwire placement decreased as individual pain tolerance increased. There was no statistically significant sex difference in selfreported pain after archwire placement.

\section{Disclosure}

The authors report no conflicts of interest in this work.

\section{References}

1. Scheurer PA, Firestone AR, Burgin WB. Perception of pain as a result of orthodontic treatment with fixed appliances. Eur J Orthod. 1996; 18(4):349-357.

2. Lew KK. Attitudes and perceptions of adults towards orthodontic treatment in an Asian community. Community Dent Oral Epidemiol. 1993;21(1):31-35.

3. Farzanegan F, Zebarjad SM, Alizadeh S, Ahrari F. Pain reduction after initial archwire placement in orthodontic patients: a randomized clinical trial. Am J Orthod Dentofacial Orthop. 2012;141(2):169-173.

4. Melzack R, Wall PD. Pain mechanisms: a new theory. Science. 1965;150(3699):971-979.

5. Bergius M, Kiliaridis S, Berggren U. Pain in orthodontics. A review and discussion of the literature. J Orofac Orthop. 2000;61(2):125-137.

6. Krishnan V. Orthodontic pain: from causes to management - a review. Eur J Orthod. 2007;29(2):170-179.

7. Polat O, Karaman AI. Pain control during fixed orthodontic appliance therapy. Angle Orthod. 2005;75(2):214-219.

8. Polat O, Karaman AI, Durmus E. Effects of preoperative ibuprofen and naproxen sodium on orthodontic pain. Angle Orthod. 2005; 75(5):791-796.

9. Eslamian L, Borzabadi-Farahani A, Hassanzadeh-Azhiri A, Badiee MR, Fekrazad R. The effect of 810-nm low-level laser therapy on pain caused by orthodontic elastomeric separators. Lasers Med Sci. 2014 29(2):559-564.

10. Lim HM, Lew KK, Tay DK. A clinical investigation of the efficacy of low level laser therapy in reducing orthodontic postadjustment pain. Am J Orthod Dentofacial Orthop. 1995;108(6):614-622.

11. Allgood JP. Transcutaneous electrical neural stimulation (TENS) in dental practice. Compend Contin Educ Dent. 1986;7(9):640,642-644.

12. Marie SS, Powers M, Sheridan JJ. Vibratory stimulation as a method of reducing pain after orthodontic appliance adjustment. J Clin Orthod. 2003;37(4):205-208; quiz 203-204.

13. Abu Alhaija ES, Aldaikki A, Al-Omairi MK, Al-Khateeb SN. The relationship between personality traits, pain perception and attitude toward orthodontic treatment. Angle Orthod. 2010;80(6):1141-1149.

14. Bergius M, Broberg AG, Hakeberg M, Berggren U. Prediction of prolonged pain experiences during orthodontic treatment. Am J Orthod Dentofacial Orthop. 2008;133(3):339.e1-339.e8.

15. Walsh NE, Schoenfeld L, Ramamurthy S, Hoffman J. Normative model for cold pressor test. Am J Phys Med Rehabil. 1989;68(1):6-11.

16. Strulov L, Zimmer EZ, Granot M, Tamir A, Jakobi P, Lowenstein L. Pain catastrophizing, response to experimental heat stimuli, and postcesarean section pain. J Pain. 2007;8(3):273-279.

17. Pan PH, Coghill R, Houle TT, et al. Multifactorial preoperative predictors for postcesarean section pain and analgesic requirement. Anesthesiology. 2006;104(3):417-425.

18. Werner MU, Duun P, Kehlet H. Prediction of postoperative pain by preoperative nociceptive responses to heat stimulation. Anesthesiology. 2004;100(1):115-119; discussion 115A.

19. Mitchell LA, MacDonald RA, Brodie EE. Temperature and the cold pressor test. J Pain. 2004;5(4):233-237.

20. Peyron R, Garcia-Larrea L, Gregoire MC, et al. Haemodynamic brain responses to acute pain in humans: sensory and attentional networks. Brain. 1999;122(pt 9):1765-1780. 
21. Keefe FJ, Lumley M, Anderson T, Lynch T, Studts JL, Carson KL. Pain and emotion: new research directions. J Clin Psychol. 2001;57(4):587-607.

22. Wang J, Tang X, Shen Y, et al. The correlations between health-related quality of life changes and pain and anxiety in orthodontic patients in the initial stage of treatment. Biomed Res Int. 2015;2015:725913.

23. Sergl HG, Klages U, Zentner A. Pain and discomfort during orthodontic treatment: causative factors and effects on compliance. Am J Orthod Dentofacial Orthop. 1998;114(6):684-691.

24. Seymour RA, Simpson JM, Charlton JE, Phillips ME. An evaluation of length and end-phrase of visual analogue scales in dental pain. Pain. 1985;21(2):177-185.

25. Abu-Saad H. Assessing children's responses to pain. Pain. 1984; 19(2):163-171.

26. Sandhu SS, Sandhu J. A randomized clinical trial investigating pain associated with superelastic nickel-titanium and multistranded stainless steel archwires during the initial leveling and aligning phase of orthodontic treatment. J Orthod. 2013;40(4):276-285.

27. Pringle AM, Petrie A, Cunningham SJ, McKnight M. Prospective randomized clinical trial to compare pain levels associated with 2 orthodontic fixed bracket systems. Am J Orthod Dentofacial Orthop. 2009;136(2):160-167.

28. Fleming PS, Johal A. Self-ligating brackets in orthodontics. A systematic review. Angle Orthod. 2010;80(3):575-584.
29. Riley JL 3rd, Robinson ME, Wise EA, Myers CD, Fillingim RB. Sex differences in the perception of noxious experimental stimuli: a metaanalysis. Pain. 1998;74(2-3):181-187.

30. Fillingim RB, King CD, Ribeiro-Dasilva MC, Rahim-Williams B, Riley JL 3rd. Sex, gender, and pain: a review of recent clinical and experimental findings. J Pain. 2009;10(5):447-485.

31. Klatzkin RR, Mechlin B, Girdler SS. Menstrual cycle phase does not influence gender differences in experimental pain sensitivity. Eur J Pain. 2010;14(1):77-82.

32. Kowalczyk WJ, Evans SM, Bisaga AM, Sullivan MA, Comer SD. Sex differences and hormonal influences on response to cold pressor pain in humans. J Pain. 2006;7(3):151-160.

33. Jones $\mathrm{M}$, Chan $\mathrm{C}$. The pain and discomfort experienced during orthodontic treatment: a randomized controlled clinical trial of two initial aligning arch wires. Am J Orthod Dentofacial Orthop. 1992;102(4): 373-381.

34. Erdinc AM, Dincer B. Perception of pain during orthodontic treatment with fixed appliances. Eur J Orthod. 2004;26(1):79-85.

35. Ngan P, Kess B, Wilson S. Perception of discomfort by patients undergoing orthodontic treatment. Am J Orthod Dentofacial Orthop. 1989; 96(1):47-53.
Patient Preference and Adherence

\section{Publish your work in this journal}

Patient Preference and Adherence is an international, peer-reviewed, open access journal that focuses on the growing importance of patient preference and adherence throughout the therapeutic continuum. Patient satisfaction, acceptability, quality of life, compliance, persistence and their role in developing new therapeutic modalities and compounds to optimize

\section{Dovepress}

clinical outcomes for existing disease states are major areas of interest for the journal. This journal has been accepted for indexing on PubMed Central. The manuscript management system is completely online and includes a very quick and fair peer-review system, which is all easy to use. Visit http://www dovepress.com/testimonials.php to read real quotes from published authors. 